\title{
Factors affecting birth weight in Cape Coast, Ghana
}

\author{
James Prah $^{1}$ *, Elvis O. Ameyaw ${ }^{2}$, Richmond Afoakwah $^{2}$, Andreas Kudom ${ }^{3}$ \\ ${ }^{1}$ University of Cape Coast Hospital, P.M.B Cape Coast, Ghana \\ ${ }^{2}$ Department of Biomedical and Forensic Sciences, University of Cape Coast, P.M.B, Cape Coast, Ghana \\ ${ }^{3}$ Department of Entomology and Wildlife, University of Cape Coast, P.M.B, Cape Coast, Ghana
}

Received: 07 March 2016

Accepted: 04 April 2016

*Correspondence:
Dr. James Prah,
E-mail: j_prah@yahoo.com

Copyright: (c) the author(s), publisher and licensee Medip Academy. This is an open-access article distributed under the terms of the Creative Commons Attribution Non-Commercial License, which permits unrestricted non-commercial use, distribution, and reproduction in any medium, provided the original work is properly cited.

\begin{abstract}
Background: This study aimed at determining the incidence of low birth weight among live births and maternal anaemia and to investigate the association between some maternal factors and birth weight.

Methods: This was a retrospective cross sectional study that involved mothers who regularly attended antenatal clinics and had delivered singleton live births between January 2014 to December 2014 in the University of Cape Coast Hospital, Cape Coast, Ghana.

Results: Out of the 405 newborns included in the study, 194 (47.90\%) were females and $211(52.10 \%)$ males with a mean birth weight of $3.25 \pm 0.52 \mathrm{~kg}$. There was a low birth weight prevalence of $7.7 \%$ and a maternal anaemia prevalence of $38.8 \%$. The period of gestation $(p=0.00001)$, maternal anaemia $(p=0.0217)$ and maternal age $(p=0.0030)$ were found to be significantly associated with birth weight. Sex of baby $(p=0.6668)$, parity of mother $(p=0.6959)$ and maternal sickling status $(\mathrm{p}=0.7915)$ were not significantly associated with birth weight.

Conclusions: As far as low birth weight is concerned, frequency is not high among live babies born to mothers who regularly attended antenatal clinics. This agrees with studies that suggest that antenatal clinic attendance positively affects birth weight. Thus in order to reduce the high prevalence of low birth weight and maternal anaemia in developing countries all pregnant women must be encouraged to attend antenatal clinics regularly.
\end{abstract}

Keywords: Birth weight, Anaemia, Term, Maternal age, Cape coast, Antenatal

\section{INTRODUCTION}

Birth weight is an important indicator of the general health status of any country or region. Low birth weight (LBW) infants are those who weigh less than $2.5 \mathrm{~kg}$ at birth. ${ }^{1}$ These include those that are born pre- term $(<37$ weeks of gestation) and those that are delivered after a full gestation period of $37-40$ weeks but due to intrauterine growth retardation (IUGR) their birth weights are below $2.5 \mathrm{~kg}$ or both. ${ }^{1}$ Worldwide, over 20 million babies are born weighing less than $2.5 \mathrm{~kg}$ accounting for $15.5 \%$ of all live births. ${ }^{2}$ The nutritional state of a pregnant woman greatly affects the weight of her baby. Therefore mothers who live in deprived socio-economic conditions frequently have low birth weight infants. The incidence of low birth weight in developed countries $(7 \%)$ is about half that of developing nations (16.5\%). As much as $95 \%$ of all low birth weight babies are born in developing countries. The average incidence of low birth weight babies in Africa is $14.3 \% .^{2}$ According to the Ghana Demographic Health Survey (GDHS), $10 \%$ of all new-borns in Ghana have low birth weight. ${ }^{3}$

It has been estimated that, the risk of neonatal death among term infants weighing less than $2.5 \mathrm{~kg}$ at birth is four times higher than that of term infants weighing between $2.5 \mathrm{~kg}$ and $3.0 \mathrm{~kg} .{ }^{4}$ Low birth weight babies have increased risk of diarrhoeal diseases and pneumonia compared to normal weight babies. ${ }^{4}$ Low birth weight is also associated with inhibited growth and cognitive development, and chronic diseases later in life. ${ }^{2}$ Maternal anaemia during pregnancy is a major cause of prematurity and low birthweight. ${ }^{5}$ Several studies have sought to find the determinants of neonatal birth weight. Some of them have found significant associations between birth weight of babies and maternal 
characteristics such as maternal haemoglobin levels during pregnancy, maternal age and parity and maternal economic status, whilst other studies found no such significant associations between anaemia in mother, parity of mother, maternal age and birth weight of babies. $^{6-9}$

Although many studies in Ghana have attempted to determine relationships between maternal characteristics and birth weights of babies, only a few of them were hospital based. We therefore undertook this study to define the extent of low birth weight problem among infants born in a hospital in Cape Coast, the capital town of the Central Region of Ghana and also to determine the mean actual birth weight of these infants. This study in addition investigated the relationship between maternal characteristics such as maternal age, parity, and maternal anaemia as well as sex of baby and their relationship with neonatal birth weight.

\section{METHODS}

The study was a hospital-based cross sectional retrospective study. The study was conducted at the University of Cape Coast Hospital which recorded 1400 deliveries in 2014. The University of Cape Coast Hospital is located in Cape Coast in the Central region of Ghana. The hospital provides primal level health care to the people of Cape Coast and surrounding communities. Sample size determination was done using a formula described earlier. ${ }^{10}$ A total of 405 mothers who had delivered at the University of Cape Coast (UCC) Hospital irrespective of mode of delivery between January 2014 and December 2014 were recruited into the study using systematic random sampling with a sample interval of two calculated using the formula $\mathrm{k}=\mathrm{N} / \mathrm{n}$

Where $\mathrm{k}$ is the sampling interval, $\mathrm{N}$ is the population size and $\mathrm{n}$ is the sample size. ${ }^{11}$ The inclusion criteria were term singleton live born babies, and the mother should have attended antenatal clinic at least three times before delivery. Mothers with multiple pregnancies and babies born dead were excluded from the study. Relevant information related to maternal characteristics namely maternal age, parity, and sickling status were obtained from the antenatal clinic records. Pre-delivery maternal haemoglobin levels which were measured at the time of admission for delivery and neonatal birth weights were obtained from the labour ward delivery register. Birth weight was measured by triple beam balance without clothing under radiant warmer to the nearest $1 \mathrm{gm}$. Gestational age was determined using a pelvic scan done in the first trimester. The haemoglobin level was determined using Hematology Analyser (Abbott CellDyn CD-1800). In this study anaemia in pregnancy was defined as haemoglobin $(\mathrm{Hb})$ concentration of less than $11.0 \mathrm{~g} / \mathrm{dl} .^{12}$

Ethical approval was obtained from the University of Cape Coast Institutional Review Board. Since this was a retrospective study informed consent was not obtained from participants.
Data was analysed using SPSS version 20 statistical software. Chi-square test was used to study the significance of difference between proportions of categorical outcomes such as maternal age, parity, maternal anaemia and birth weight with the level of significance set at $\mathrm{p}<0.05$.

\section{RESULTS}

Table 1: Distribution of birth weight by gestational age.

\begin{tabular}{|lllllll|}
\hline \multirow{2}{*}{$\begin{array}{l}\text { Gestational } \\
\text { age }\end{array}$} & \multicolumn{3}{c}{ Observation } & \multicolumn{4}{c|}{ Birth weight (kg) } \\
\cline { 2 - 7 } & $\mathrm{n}$ & $\%$ & $\mathrm{n}$ & $\%$ & $\mathrm{n}$ & $\%$ \\
\hline Pre-term & 39 & 11.11 & 15 & 48.39 & 24 & 11.23 \\
\hline term & 366 & 88.88 & 16 & 51.61 & 350 & 88.77 \\
\hline Total & 405 & 100 & 31 & 100 & 374 & 100 \\
\hline
\end{tabular}

$\mathrm{X}^{2}=57.95 ; \mathrm{p}=0.00001$; *significant

Table 2: Distribution of birth weight by maternal sickling status.

\begin{tabular}{|c|c|c|c|c|c|c|}
\hline \multirow{3}{*}{$\begin{array}{l}\text { Maternal } \\
\text { sickling } \\
\text { status }\end{array}$} & \multirow{2}{*}{\multicolumn{2}{|c|}{ Observation }} & \multicolumn{4}{|c|}{ Birth weight (kg) } \\
\hline & & & \multicolumn{2}{|c|}{$<2.5$} & \multicolumn{2}{|c|}{$\geq 2.5$} \\
\hline & $\mathrm{n}$ & $\%$ & $\mathrm{n}$ & $\%$ & $\mathrm{n}$ & $\%$ \\
\hline positive & 45 & 11.11 & 3 & 9.68 & 42 & 11.23 \\
\hline negative & 360 & 88.88 & 28 & 90.32 & 332 & 88.77 \\
\hline Total & 405 & 100 & 31 & 100 & 374 & 100 \\
\hline
\end{tabular}

$\mathrm{X}^{2}=0.0699 ; \mathrm{p}=0.791535 ;{ }^{*}$ not significant

The actual mean weight of the new born in the study was $3.26 \pm 0.52 \mathrm{~kg}$. Out of the 405 new babies included in the study, $194(47.9 \%)$ were females and $211(52.1 \%)$ were males. The mean birth weight of the males was $3.27 \pm 0.49$ $\mathrm{kg}$ and that of the females was $3.25 \pm 0.53 \mathrm{~kg}$ showing that the males generally weighed heavier than the females, but the difference was not significant statistically $(\mathrm{p}=0.666)$. A total of $31(7.7 \%)$ of new-borns weighed less than $2.5 \mathrm{~kg}$ whilst $374(92.3 \%)$ weighed more than $2.5 \mathrm{~kg}$, thus the study found a low birth weight (LBW) incidence rate of $7.7 \%$. The mean age of the mothers was $22.5 \pm 2.92$ years. A total of $170(41.97 \%)$ were within the age group of 25 and 30 years whilst 20(4.93\%) were under 19 years. The mean age of mothers whose babies weighed $<2.5 \mathrm{~kg}$ was $22.8 \pm 3.02$ years, while mean age of mothers whose babies weighed $\geq 2.5 \mathrm{~kg}$ was $22.3 \pm 2.72$ years. Maternal age was significantly associated with birth weight $(\mathrm{p}=0.0030)$. In general, low birth weight cases were recorded across the age spectrum. However, the mean birth weight of babies born to mothers' $<19$ years was $2.98 \pm 0.56 \mathrm{~kg}$ which was lower than the mean birth weight of babies whose mothers were $\geq 19$ years $(3.29 \pm 0.46 \mathrm{~kg})$. Of the 20 mothers aged $<19$ years, $6(30.0 \%)$ gave birth to LBW babies whilst $25(6.49 \%)$ of mothers aged $\geq 19$ years delivered LBW babies. Out of the 31 babies who were of LBW, $11(35.48 \%)$ of them were the first children of their mothers whilst multiparous women delivered $20(64.52 \%)$ of the LBW babies. There was however no significant difference in the mean birth 
weights among the different parity groups $(p=0.6959)$. The period of gestation showed a significant association with birth weight (Table 1).

The study found that maternal anaemia was significantly associated with birth weight of babies $(p=0.0217)$. However, there was no significant association between sex of baby $(\mathrm{p}=0.6668)$ and the sickling status of mother $(\mathrm{p}=0.7915)$ and neonatal birth weight. Table 2 shows the distribution of sickling status of mothers and the birth weights of their babies.

Table 3: Association of haemoglobin of mothers and birth weight.

\begin{tabular}{|c|c|c|c|c|c|c|}
\hline \multirow{3}{*}{$\begin{array}{l}\text { Maternal } \\
\text { haemoglobin } \\
\text { (g/dl) }\end{array}$} & \multirow{2}{*}{\multicolumn{2}{|c|}{ observation }} & \multicolumn{4}{|c|}{ Birth weight (kg) } \\
\hline & & & \multicolumn{2}{|c|}{$<2.5$} & \multicolumn{2}{|c|}{$\geq 2.5$} \\
\hline & $\mathrm{n}$ & $\%$ & $\mathrm{n}$ & $\%$ & $\mathrm{n}$ & $\%$ \\
\hline$<11$ & 157 & 38.8 & 18 & 58.06 & 139 & 37.17 \\
\hline$\geq 11$ & 248 & 61.2 & 13 & 41.94 & 235 & 62.83 \\
\hline Total & 405 & 100 & 31 & 100 & 374 & 100 \\
\hline
\end{tabular}

At the time of delivery $157(38.8 \%)$ of the mothers had haemoglobin levels of $<11.0 \mathrm{~g} / \mathrm{dl}$. Maternal anaemia was significantly associated with birth weight (Table 3 ).

\section{DISCUSSION}

In the present study, the prevalence of LBW was found to be $7.7 \%$ which is lower than the Ghana national prevalence of $10 \%$ and the prevalence for Africa (14.3\%) and Western Africa (15.4\%). ${ }^{3}$ It is however comparable to the prevalence of developed nations (7\%). A similar hospital based study conducted in Nigeria found a LBW prevalence rate of $7.2 \% .^{13}$ The prevalence found in this study is slightly lower than the prevalence of $8.0 \%$ found in an earlier study for the Central region of Ghana. ${ }^{3}$ The difference could be due to the difference in study designs, study site and years between the studies. ${ }^{3}$ Even though this study and the earlier study both used live births, the current study is hospital based whilst the earlier study was a demographic health survey that included births other than hospital births. The findings of this study also agree with other studies that found that women with inadequate antenatal care tended to deliver LBW babies but contradicts findings from some studies that found no significant relationship between number of antenatal visits and LBW. ${ }^{14,15}$ In Ghana, there is evidence that many more pregnant women now attend antenatal clinics where they are given iron supplements and are educated on good nutritional habits. According to the Ghana Demographic Health Survey, 2014, about 97\% of pregnant women in Ghana receive antenatal care from a skilled provider. ${ }^{3}$ This improvement in antenatal clinic attendance may have contributed to the lower incidence of LBW found in this study. The study found that maternal age has a significant association with birth weight. Earlier studies have also reported that young mothers had higher incidence of LBW than older mothers. ${ }^{6,7}$ The period of gestation was significantly associated with birth weight. This relationship has been well studied by many investigators with their findings forming the basis of the curves used to create the WHO "universal" gestation specific growth charts. ${ }^{9}$ In this study, the mean age of mothers who gave birth to normal weight babies found to be $22.3 \pm 2.72$ years was in agreement with a previous study conducted by WHO which had showed that the normal age range of mothers whose babies weighed more than $2.5 \mathrm{~kg}$ was $21-30$ years. ${ }^{16}$ Also the actual mean birth weight found in this study is consistent with the findings of a previous study that found the normal birth weight in both male and female new-borns to be $2.5 \mathrm{~kg}$ to $3.5 \mathrm{~kg} .{ }^{17}$ In this study, the mean birth weight of males was $3.27 \pm 0.49 \mathrm{~kg}$ and that of the females was $3.25 \pm 0.53 \mathrm{~kg}$ confirming the findings from an earlier study suggesting that male babies were generally heavier than female babies. ${ }^{17}$ The present study also found that babies born to mothers who were aged $<19$ years had a lower mean birth weight compared to babies whose mothers were more than 19 years of age. These findings are similar to other studies that have documented a tendency of increasing birth weight with maternal age. ${ }^{18,19}$ The study revealed that $20(5 \%)$ of the mothers were under 19 years of age. Among these mothers $30 \%$ delivered babies with low birth weight. ${ }^{6}$ This is worrying because children born to very young mothers are at increased risk of sickness and death. Teenage mothers are more likely to experience adverse pregnancy outcomes and are more constrained in their ability to provide educational opportunities than young women who delay childbearing. Teenage (13-19 years) pregnancies are a common phenomenon in Ghana, in spite of legal constraints. Under the laws of Ghana, the relevant laws are the Marriages Act 1884-1985 and the Children's Act $1998 .^{20}$ The Children's Act 1998 provides in section 13 (2) that a person of 18 years and above may legally enter into marriage.

The study also found that $38.8 \%$ of the mothers were anaemic at the time of delivery. This prevalence rate found in the present study is lower than the estimated prevalence rate of $40 \%$ to $60 \%$ in developing countries ${ }^{1}$ but higher than the $23 \%$ rate recorded for developed countries. $^{12,21}$ In a previous study in Ghana, $44.6 \%$ of pregnant women were found to be anaemic. ${ }^{3}$ Although the finding in this present study shows an improvement in the prevalence of maternal anaemia, it is still well below that of developed countries. Even though many more pregnant women are now regularly receiving antenatal care, there is still a high level of maternal anaemia probably because the mothers are still not feeding well possibly due to poverty, malaria in pregnancy is still high, only a few $(39 \%)$ take intestinal parasite medicines prescribed at the antenatal clinics because of fear of side effects. $^{3,22}$ Although findings from this study suggests that antenatal clinic attendance is beneficial to both the pregnant woman and her baby, the prevalence of maternal anaemia found in Cape Coast is still high and therefore it is recommended that medical experts involved in health care provision to pregnant women should advise them to 
take in foods and or supplements that will increase their haemoglobin levels, to protect themselves against being infected with malaria by sleeping in insecticide treated bed nets and pharmacists dispensing the drugs should reassure them of the safety of drugs prescribed at the antenatal clinics so that adherence to medications will increase. Drug safety campaigns conducted by Pharmacists in Ghana have over the years targeted mainly non-pregnant women. These programmes should also include the safety of drugs used in pregnancy in order to equip pregnant women with the knowledge and eventually, confidence to adhere to medications prescribed for them. Teenage pregnancies should be actively discouraged in the Central region of Ghana which has one of the highest rates of live births among teenagers in Ghana. ${ }^{3}$ The concerned authorities should formulate appropriate reproductive health promotion programs that will discourage early pregnancies and encourage late motherhood. Effectively implementing such policies will be beneficial as it will help reduce the rate of LBW among mothers in the region which will impart positively on the achievement of the Sustainable Development Goal that seeks to ensure healthy lives and promote well-being for all at all ages.

\section{CONCLUSION}

This study shows that among babies born in a hospital by mothers who were regular antenatal clinic attendants, the incidence of low birth weight is low and therefore in order to reduce the high prevalence of low birth weight in developing countries like Ghana, every pregnant woman should be encouraged to regularly attend antenatal clinic.

\section{ACKNOWLEDGEMENTS}

The authors are grateful to the staff and management of the University of Cape Coast Hospital for making this study possible.

\section{Funding: No funding sources}

Conflict of interest: None declared

Ethical approval: The study was approved by the Institutional Ethics Committee

\section{REFERENCES}

1. WHO. 1984: The Incidence of low birth weight: an update. Wkly Epidemol Rec. 1984;59:205-11.

2. United Nations Children's Fund and World Health Organization, 2004. Low Birth weight: Country, regional and global estimates. UNICEF, New York, 2004.

3. Ghana Demographic Health Survey, 2014.

4. World Nutrition Situation. Geneva. 2000: ACC/SCN in collaboration with IFPRI.

5. Chang SC, O'Brien KO, Nathanson MS, Mancini J, Witter FR. Hemoglobin concentrations influence birth outcomes in pregnant African-American adolescents. J Nutr. 2003,133:2348-55.

6. Hassan NE, Shalaan AH, El-Masry SA. Relationship between maternal characteristics and neonatal birth size in Egypt Eastern Mediterranean Health Journal EMHJ. 2011;17(4):281-9.

7. Cramer JC. Racial and ethnic difference in birth weight: The role of income and financial assistance. Demography. 1995:32:231-47.

8. Pakrasi K, Sil S, Dasgupta P, Dasgupta I. Pattern of lowbirth weight in the Bengali newborns. Indian J. Phys. Hum.Genet., 1985;11: 107-22.

9. Joshi SM, Likhar SK, Athavale AV, Shukla US. Factors Affecting Birth Weight: A Study in a SecondaryLevel Hospital in Gas Affected Area of Bhopal. Natl J Community Med. 2013;4(4):570-3.

10. Fisher LD. (1998). Self-designing clinical trials. Stat. Med. 1998;17:1551-62.

11. Black K. Business Statistics for Contemporary Decision Making (Fourth (Wiley Student Edition for India) ed.). 2004. Wiley-India. ISBN 978-81-2650809-9.

12. WHO. Iron deficiency anaemia, assessment, prevention and control. A Guide for Programme Manangers. Geneva, Switzerland: 2001. WHO.

13. Umar A, Barnabas D., Murtala M.J, Ismaila A. Retrospective Study of Maternal age and Birth Weight in Abubakar Tafawa Balewa University Teaching Hospital (ATBUTH) Bauchi State, Nigeria. Asian J Med Pharm. Res. 2014;4(1):1-4.

14. Ashraf-ganjoei $T$, Mirzaei F, Anari-dokht $F$. Relationship between prenatal care and the outcome of pregnancy in low-risk pregnancies. Open J Obstet Gynecol. 2011;1:109-12.

15. Abdal Qader MA, Badilla I, Mohd Amin R, Ghazi HF. Influence of antenatal care on birth weight: a cross sectional study in Baghdad City, Iraq. BMC Public Health. 2012;12(Suppl 2):A38..

16. WHO database on LBW. A tabulation of available information. WHO (MCH) 92.2 World Health Organization Geneva. 1992;1(2):5.

17. Millis J, Seng YP. The effect of age and parity of the mother on birth weight of the offspring. Ann. Hum. Genet. 1954;19(2):58-73.

18. Khanam S, Islam MN, Kawser CA. Maternal and Socioeconomic risk factors associated with how birth weight. Bangladesh J Child health. 1995;19:112-6.

19. Makhija K, Murthy GVS. Socio-biologic factors influencing low birth weight at rural project hospital. J Indian Med Assoc. 1990;88(3):215-21.

20. Constitution of Ghana, 1992

21. WHO. Prevention and management of severe anaemia in pregnancy. WHO/FHE/MSM/ 1993:93-5.

22. Ofori M, Ansah E, Agyepong I, Ofori-Adjei D, Hviid L, Akanmori B. Pregnancy-Associated Malaria in a Rural Community of Ghana. Ghana Med J. 2009;43(1):13-8.

Cite this article as: Prah J, Ameyaw EO,

Afoakwah R, Kudom A. Factors affecting birth weight in Cape Coast, Ghana. Int J Reprod Contracept Obstet Gynecol 2016;5:1536-9. 